\title{
Micro- and meso-scale variability in sediment activity concentrations: The implications for dose assessment
}

\author{
D.J . Assinder, S.M. Mudge and A.T. Russell \\ School of Ocean Sciences, University of Wales, Bangor, Menai Bridge LL59 5AB, Wales, UK
}

\begin{abstract}
Radionuclides in the environment require regular monitoring to establish activity concentrations and make reliable dose estimates. This study examines the variability in selected radionuclide activity concentrations at a variety of spatial scales and assesses the resulting errors in dose estimates. The Ribble Estuary, UK provides an ideal location to conduct non-destructive tests ( $\beta$-dose rate measurements) due to the discharge of ${ }^{234} \mathrm{Th}$ and ${ }^{234 \mathrm{~m}} \mathrm{~Pa}$ from the BNFL fuel fabrication plant at Springfields (Lancashire, UK). This estuary also receives Sellafield derived radionuclides after transport through the Irish Sea. Results indicate that significant errors in external beta and gamma dose assessments may result from the use of single sediment activity concentration or dose values to represent an area of contaminated sediment. For example, in an area only $1 \mathrm{~m}$ x $1 \mathrm{~m}$ square, a field coefficient of variation for beta dose may be as high as $25 \%$, even when there are no visible textural or compositional variations to account for this, and this increased to $83 \%$ at the $100 \times 100 \mathrm{~m}$ scale. Erroneous conclusions on the nature of change in time-series measurements can be made if local field variability has not been assessed and allowed for when planning the monitoring programme.
\end{abstract}

\section{INTRODUCTION}

Artificial and natural radionuclides in the environment require regular measurement to establish activity concentrations and make reliable dose estimates. Most monitoring and sampling programmes involving sediments and soils are solely based on the analysis of a single sample to characterise an area or time period. Results are usually presented with analytical errors although the micro (e.g. $1 \mathrm{~m} x 1 \mathrm{~m}$ ) and meso-scale (e.g. 100m x 100m) heterogeneity of contaminant concentrations, or 'field variability', is rarely considered. This may well compromise the ability to determine trends both temporally and spatially and to correctly calculate doses to man.

From 1991 to 2002, measurements of a variety of natural, technologically-enhanced natural and artificial radionuclides have been made in north-west UK estuaries to establish the degree of field variability present in activity concentrations. Detailed results from these studies are presented in a series of reports and papers [1-6]. This paper summarises the main findings and assesses the main implications for dose assessment to man in the Ribble Estuary, UK. This estuary provides an ideal location to conduct non-destructive tests ( $\beta$-dose rate measurements) due to the discharge of ${ }^{234} \mathrm{Th}$ and ${ }^{234 \mathrm{~m}} \mathrm{~Pa}$ from the BNFL fuel fabrication plant at Springfields (Lancashire, UK); it also receives Sellafield derived radionuclides after transport through the Irish Sea. This is part of a larger study of the practice of monitoring and repeat measurements which is considering the problems of repeat visits to the 'same site' [7] including:

- the collection of a 'representative' surface sediment sample at a site which reflects recent inputs of the contaminant

- $\quad$ the inherent analytical and counting error associated with the measurement of a radionuclide in a single sediment sample

- the re-positioning error when re-visiting a particular site to sample on future occasions, particularly when sampling offshore from research vessels 
- the inherent small-scale variability in radionuclide activity concentrations in sediments due to 'patchiness' in initial contamination from the source, sediment compositional differences, sediment grain surface area variations which influence the amounts of radionuclides which the grains can adsorb onto their surfaces

- the action of further inputs or losses, e.g. radionuclide redistribution or remobilisation processes due to tidal or riverine action, from the sediments at that site during the intervening period.

\section{METHODS}

\subsection{Field}

The research required in situ beta dose rate measurements and sediment sampling of $1 \mathrm{~m} \mathrm{x} 1 \mathrm{~m}$ and $100 \mathrm{~m} \times 100 \mathrm{~m}$ grid squares. A $1 \mathrm{~m} \times 1 \mathrm{~m}$ aluminium frame was used with an insert which allowed the Berthold beta dose LB1210B meter and a sediment plane, to collect surface sediment samples $(0-1 \mathrm{~cm})$, to move freely around the grid (Figure 1$)$. One metre steel rules were attached to all sides to allow accurate positioning. In the field, the grid was placed on the sediment surface and levelled relative to that surface at a constant height above the sediment [4].

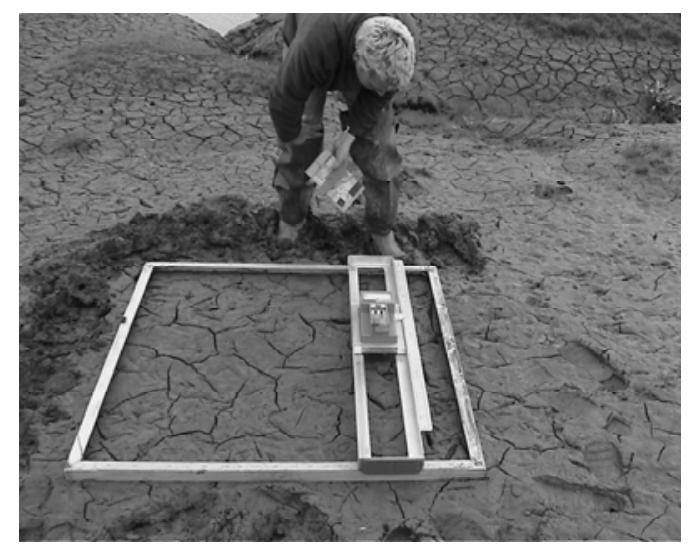

Figure 1. Beta dose rate measurement using a $1 \mathrm{~m}$ x $1 \mathrm{~m}$ aluminium frame.

Beta dose rate measurements were made in the Ribble Estuary, UK using standard methods [4]. In summary, the Berthold LB1210B is used to give a combined beta and gamma count rate from the sediment surface. A repeat measurement is then made using a perspex/aluminium shield over the detector surface to remove the beta component and yield a gamma measurement only. The beta count rate value can then be obtained by subtraction. A conversion to beta dose rate is then made using the instrument calibration.

\subsection{Laboratory}

Radionuclide analyses were performed on the surface sediment samples by conventional gammaspectrometric techniques using an ORTEC GAMMA-X n-type Ge detector and computerised gamma spectrometry system [1]. Dried sediment samples were placed into vials and packed to standard geometries for counting. The instrument was calibrated with National Physical Laboratory gamma standard R08-03 for a range of sediment grain sizes and densities. Using this calibration, counts at $59.54 \mathrm{keV}\left({ }^{241} \mathrm{Am}\right), 63.29 \mathrm{keV}\left({ }^{234} \mathrm{Th}\right), 661.66 \mathrm{keV}\left({ }^{137} \mathrm{Cs}\right), 1001.03 \mathrm{keV}\left({ }^{234 \mathrm{~m}} \mathrm{~Pa}\right), 1173.24 \mathrm{keV}\left({ }^{60} \mathrm{Co}\right)$, $1332.5 \mathrm{keV}\left({ }^{60} \mathrm{Co}\right)$ and $1460.75 \mathrm{keV}\left({ }^{40} \mathrm{~K}\right)$ were converted to $\mathrm{Bq} \mathrm{kg}^{-1}$ dry weight of sediment. Quality Assurance measurements for the instrument were carried out by standard methods [3,4] using International Atomic Energy Agency inter-calibration standard IAEA-135 (Irish Sea sediment). 
Grain size analyses (as a proxy for grain surface area) were carried out by wet sieving through a $63 \mu \mathrm{m}$ sieve. Organic carbon was assessed by combustion at $450^{\circ} \mathrm{C}$.

The variability in measurements is presented as a Coefficient of Variation. The values presented are those attributable to field variability as the known analytical variance has been subtracted from the data.

\section{RESULTS}

\subsection{Beta dose rate measurements}

A typical variation of beta dose rate across a $1 \mathrm{~m} \times 1 \mathrm{~m}$ square is shown in Figure 2. A factor of 2.3 between the highest and lowest values is evident. The Coefficient of Variation for the field variability of the beta dose rate averaged $12 \%$ (range $2-20 \%$ ) at the $1 \mathrm{x} 1 \mathrm{~m}$ scale and increased to $83 \%$ at the 100x100m scale. [3,4] At the smaller scale, there was no visual or textural evidence to explain the variability although at the larger scale, grain size differences were apparent across the sampling area.

In addition, significant short-term temporal variability has been observed, even from one tide to the next [4].

\subsection{Radionuclide activity concentrations}

Activity concentrations in surface sediments of the Ribble Estuary from 1991 to 2002 ranged up to $1000 \mathrm{~Bq} \mathrm{~kg}{ }^{-1}$ for ${ }^{137} \mathrm{Cs}$, up to $500 \mathrm{~Bq} \mathrm{~kg}{ }^{-1}$ for ${ }^{241} \mathrm{Am}$ and up to $1000 \mathrm{kBq} \mathrm{kg}^{-1}$ for ${ }^{234} \mathrm{Th}$. Activity concentrations in surface sediments have fallen over time due to reductions in discharges from BNFL Sellafield and BNFL Springfields [4]. Other natural radionuclide ranges are presented elsewhere [2].

Coefficients of Variation for field variance ranged from 2 to $25 \%$ in a $1 \mathrm{~m} \mathrm{x} 1 \mathrm{~m}$ square, with no visible or textural evidence to explain the variability, to 14 to $95 \%$ in a $100 \mathrm{~m}$ x $100 \mathrm{~m}$ square with significant correlations with grain size and organic carbon variations for certain isotopes. These tended to be long-lived isotopes derived from Sellafield $\left({ }^{137} \mathrm{Cs},{ }^{241} \mathrm{Am}\right)$ where some measure of equilibrium has been attained in relation to sediment grain surface area. Shorter-lived Springfields-derived radionuclides $\left({ }^{234} \mathrm{Th}\right)$ showed less significant relationships to grain surface area proxies due to a lack of equilibrium time. An example of the variability across a $100 \mathrm{~m}$ x $100 \mathrm{~m}$ square is shown in Figure 3 where the Cs distribution shows significant correlation to the grain size distribution. Low Cs values and coarse sediment are located at the bottom of the diagram; higher Cs values are located in muds higher up the inter-tidal bank shown.

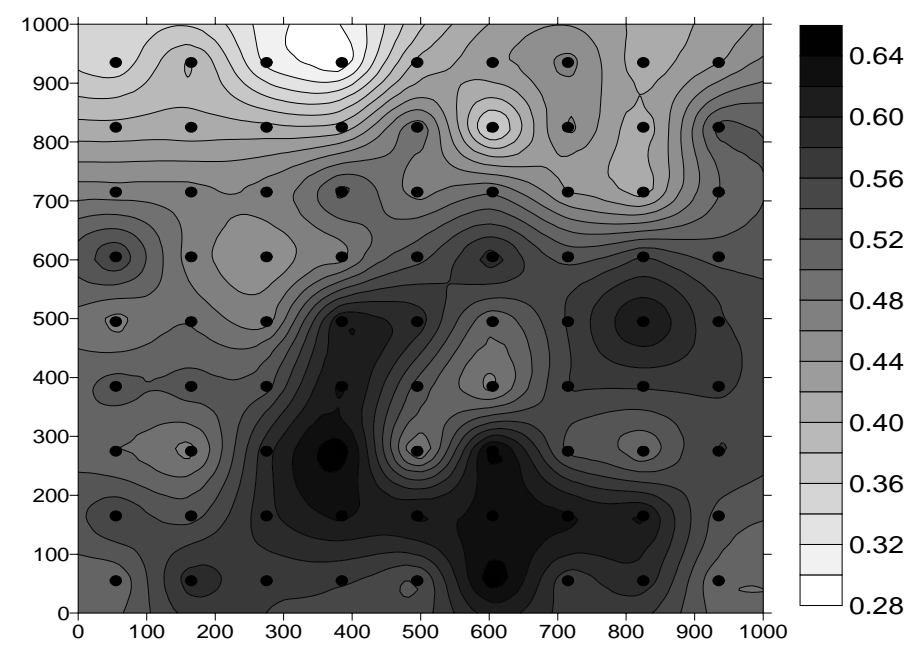

Figure 2. The beta dose rate ( $\mu \mathrm{Sv} \cdot \mathrm{h}^{-1}$ to skin) across a typical $1 \mathrm{x} 1 \mathrm{~m}$ square (axes in mm) from the Ribble Estuary. 


\subsection{Implications for cost-effective sediment monitoring}

For the $1 \mathrm{~m} \times 1 \mathrm{~m}$ squares, a reliable mean value for activity concentration and dose rate can be obtained most cost-effectively by averaging four values taken in each of the four $0.25 \mathrm{~m} \times 0.25 \mathrm{~m}$ quadrants within the overall area [3]. At the $100 \mathrm{~m} \times 100 \mathrm{~m}$ scale, grain surface area proxy relationships are useful to normalise data for longer-lived radionuclides when time-series sampling is desired for monitoring purposes [4]. Figure 4 illustrates the use of sediment grain size as a grain surface area proxy normaliser.

In Figure 4, the correlation for both data sets is highly significant with $r^{2}=0.78$ and $r^{2}=0.80$ for $1991 / 92$ and 1999, respectively. Using the linear regression equation, the concentration of ${ }^{137} \mathrm{Cs}$ was calculated for a given percentage $<63 \mu \mathrm{m}$, (e.g. 40\%). The activity in 1991/92 was calculated to be $298.8 \mathrm{~Bq} \mathrm{~kg}{ }^{-1}$ and in 1999 equalled $165.4 \mathrm{~Bq} \mathrm{~kg}{ }^{-1}$ a decrease of approximately $45 \%$. During this time the ${ }^{137} \mathrm{Cs}$ discharge from Sellafield had decreased by approximately $50 \%[8,9]$. This approach smoothes the inherent field variability at all spatial scales and allows the actual degree of fall of ${ }^{137} \mathrm{Cs}$ activity concentrations in Ribble Estuary sediments over the period 1991 to 1999 to be established.

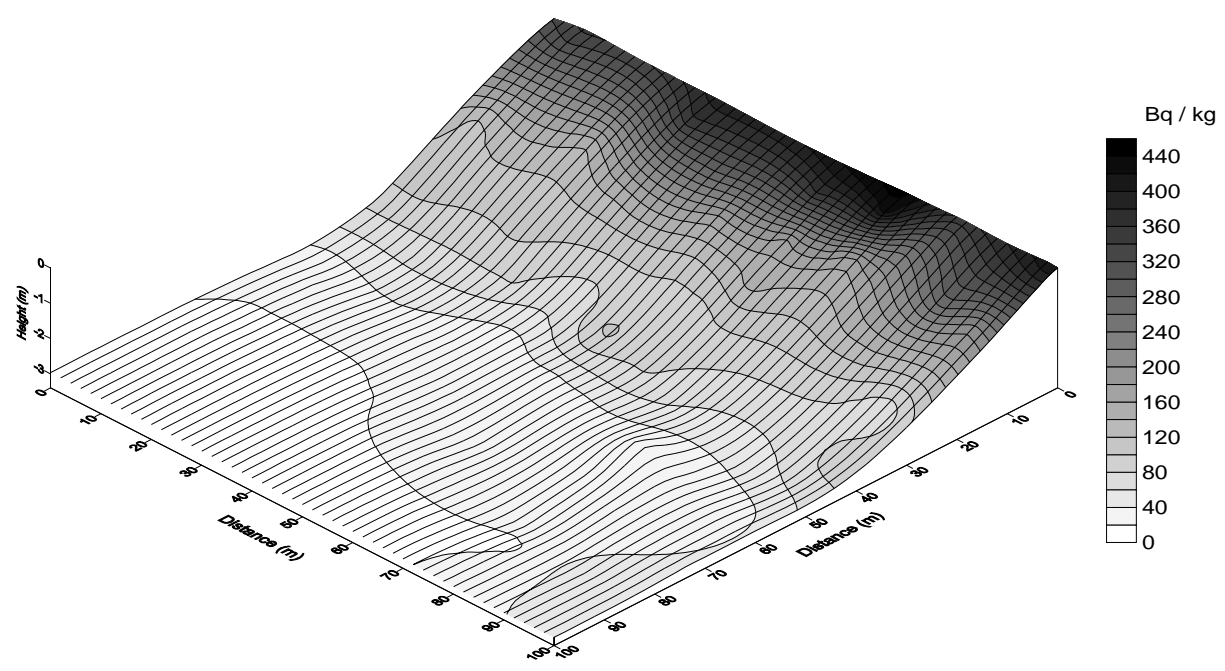

Figure 3. The ${ }^{137} \mathrm{Cs}$ activity concentration contour plot draped over the topography of the $100 \mathrm{x} 100 \mathrm{~m}$ square (67 values).

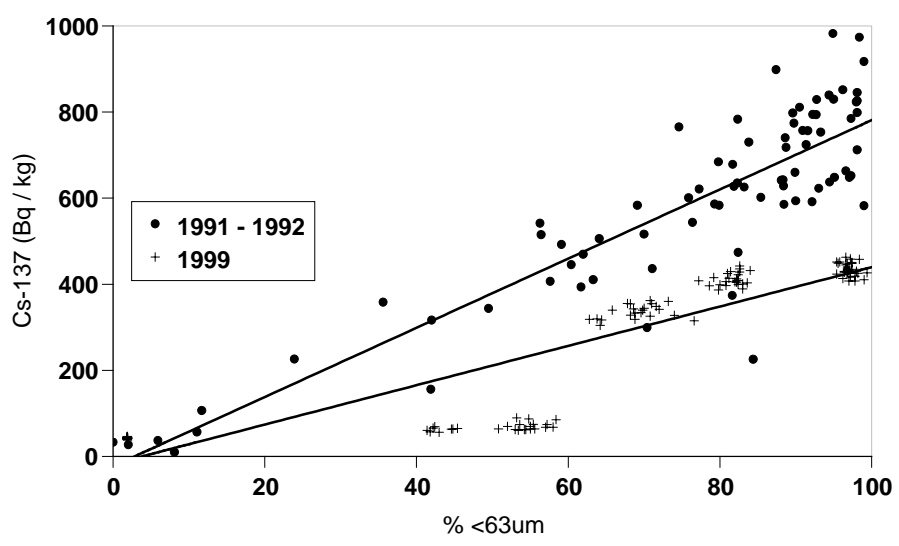

Figure 4. A graph comparing the ${ }^{137} \mathrm{Cs}$ sediment activity concentration and $\%<63 \mu \mathrm{m}$ relationships for two data sets from the Ribble Estuary. 


\section{DISCUSSION AND CONCLUSIONS}

This research has demonstrated that:

- Radionuclide activity concentrations and beta dose rate show significant variations over a $1 \mathrm{~m} \times 1 \mathrm{~m}$ area of contaminated sediment. These variations do not correlate with easily measurable sediment grain surface area proxies.

- A coefficient of variation of up to $20 \%$ may be present on measurements of dose rate across a $1 \mathrm{~m} \times 1 \mathrm{~m}$ grid.

- Radionuclide activity concentrations and beta dose rate show significant variations over a $100 \mathrm{~m}$ x $100 \mathrm{~m}$ area of contaminated sediment. Longer-lived radionuclide activity concentration variations correlated with easily measurable grain surface area proxies whereas shorter-lived, locally sourced radionuclides did not.

- A coefficient of variation of up to $83 \%$ may be present on measurements of dose rate across a $100 \mathrm{~m} \times 100 \mathrm{~m}$ grid if no account is taken of grain surface area variation.

- All results suggest that considerable care must be taken when making dose monitoring measurements above sediment or when collecting sediment samples for activity concentration measurements. Normalisation to grain surface area proxies appears to be a useful tool for certain isotopes. Erroneous conclusions on the nature of change in time-series measurements can be made if local field variability has not been assessed and allowed for when planning the monitoring programme.

\section{Acknowledgments}

The authors are grateful to the Environment Agency, UK for a research grant to carry out this work.

\section{References}

[1] Assinder D.J., Mudge S.M. and Bourne G.S., J. Env. Radioact. 36 (1997) 1 - 19.

[2] Mudge S.M., Bourne G.S. and Assinder D.J. A survey of radioactivity in the Ribble Estuary. I. Activity concentrations and estuarine dynamics. (Her Majesty's Stationery Office, UK, 1994, 68pp).

[3] Mudge S.M., Assinder D.J. and Russell A.T. Micro-scale variability of contaminants in surface sediments: the implications for sampling. (Environment Agency, UK, 2003, 88pp).

[4] Mudge S.M., Assinder D.J. and Russell A.T. Meso-scale variation of radionuclides in sediments: Normalisation and the implications for sampling. (Environment Agency, UK, 2003, 72pp).

[5] Mudge S.M., Bourne G.S. and Assinder, D.J. J. Env. Radioact. 36 (1997) 21-41.

[6] Mudge S.M., Assinder D.J. and Bourne G.S. J. Env. Radioact. 36 (1997) 43-67.

[7] Assinder D.J., The Nuclear Engineer 43 (2002) 76-79.

[8] BNFL. Annual report on radioactive discharges and monitoring of the environment, 1992. (BNFL, UK, 1993, 97pp).

[9] BNFL. Annual report on radioactive discharges and monitoring of the environment, 1999. (BNFL, UK, 2000, 163pp). 